\title{
Congenital portosystemic shunt occlusion with an Amplatzer PFO occlusion device: a case report
}

\author{
Michelle M. Shnayder ${ }^{1 *}$, Mario Dervishi ${ }^{2}$, Alexandria Jo ${ }^{1}$ and Benjamin Pomerantz ${ }^{1}$
}

\begin{abstract}
Background: Congenital portosystemic shunts are embryological malformations in which portal venous flow is diverted to the systemic circulation. High morbidity and mortality are seen in patients with concurrent hepatic encephalopathy, hepatopulmonary syndrome, and pulmonary hypertension. Endovascular therapy, in the correct patient population, offers a less invasive method of treatment with rapid relief of symptoms.

Case presentation: In this report, we discuss the treatment of a two-year-old male with abnormal chorea-like movements, altered mental status, anisocoria and hyperammonemia diagnosed with an intrahepatic congenital portosystemic shunt between the inferior vena cava and right portal vein. Given the patient's amenable anatomy and shunt type, embolization was performed with an $18 \mathrm{~mm}$ Amplatzer patent foramen ovale occlusion device.

Conclusions: Portosystemic shunts are a rare congenital abnormality without universal treatment guidelines. An Amplatzer PFO occlusion device can provide a novel method of shunt closure given appropriate shunt type, size and anatomy.
\end{abstract}

Keywords: Congenital portosystemic shunt, Extrahepatic portosystemic shunt, PFO occlusion device

\section{Introduction}

Congenital Portosystemic Shunts (CPSS) are rare developmental malformations that occur in 1 in 50,000 births. [1] Some patients remain asymptomatic and the presence of an aberrant malformation is incidentally identified on imaging. However, a subset of patients become symptomatic at an early age and have increased morbidity. Common complications of CPSS include hyperammonemia, cholestasis, liver tumors, pulmonary hypertension or hepatopulmonary syndrome. [2]

Treatment options for symptomatic shunts include endovascular occlusion, surgical ligation, liver resection, and transplantation; however, endovascular occlusion has largely become the preferred less-invasive method of

\footnotetext{
* Correspondence: shnayder@med.umich.edu

'Department of Radiology; Division of Vascular and Interventional Radiology, University of Michigan Health System, 1500 E. Medical Center Dr, B1D502, 48109-5030 Ann Arbor, MI, USA

Full list of author information is available at the end of the article
}

treating certain CPSS. Within the toolbox of endovascular occlusion options, vascular plugs and coils are frequently used with few case reports describing the use of Patent Foramen Ovale (PFO) Occlusion Devices (OD). $[3,4]$ Standard treatment guidelines for CPSS are not yet developed due to the rarity of this condition. Our report highlights the side-to-side closure of a CPSS with an Amplatzer PFO OD-an off-label use of this device.

\section{Case report}

A two-year-old male with history of Trisomy 21, atrial septal defect per echocardiogram, and autism spectrum disorder presented to the emergency department with abnormal chorea-like movements, altered mental status, anisocoria. Laboratory findings showed hyperammonemia (maximum level of $256 \mathrm{mg} / \mathrm{dL}$ ). The patient's brain computed tomography (CT) and magnetic resonance imaging (MRI) were unremarkable. Doppler ultrasound of the abdomen demonstrated an intrahepatic shunt

\section{Springer Open}

(c) The Author(s). 2021 Open Access This article is licensed under a Creative Commons Attribution 4.0 International License, which permits use, sharing, adaptation, distribution and reproduction in any medium or format, as long as you give appropriate credit to the original author(s) and the source, provide a link to the Creative Commons licence, and indicate if changes were made. The images or other third party material in this article are included in the article's Creative Commons licence, unless indicated otherwise in a credit line to the material. If material is not included in the article's Creative Commons licence and your intended use is not permitted by statutory regulation or exceeds the permitted use, you will need to obtain permission directly from the copyright holder. To view a copy of this licence, visit http://creativecommons.org/licenses/by/4.0/. 
between the right portal vein (PV) and inferior vena cava (IVC). Hepatopetal intrahepatic portal venous flow was present in diminutive PV branches. Further evaluation with contrast enhanced CT of the abdomen confirmed the presence of a CPSS. (Fig. 1) The interventional radiology service was consulted for further evaluation. Treatment options were discussed with the cardiology team, and an Amplatzer PFO OD was deemed appropriate for the patient's anatomy.

Right femoral vein access was obtained, and a venogram of the IVC confirmed a large side-to-side shunt from the anterior right lateral aspect of the IVC to a branch of the right PV measuring approximately $14 \mathrm{~mm}$ in diameter. (Fig. 2) The shunt was circumferentially surrounded by hepatic parenchyma with no additional side-branches. Due to the patient's acute condition and the high likelihood of placing the occlusion device regardless of measurements, hepatic pressures were not obtained. Through a 7 French sheath, an $18 \mathrm{~mm} \mathrm{x}$ $18 \mathrm{~mm}$ Amplatzer PFO OD (St. Jude Medical, Inc., Saint Paul, MN) was deployed across the shunt with the distal portion of the plug being deployed within the right PV branch. The sheath and plug were then retracted until the circumferential hepatic parenchymal flap resisted further traction. The second portion of the plug was subsequently deployed across the shunt and the device was detached. (Fig. 3) Post-occlusion venography showed successful shunt embolization. (Fig. 3) There were no immediate complications. Given mild bleeding from the right femoral puncture site due to patient movement, short-term anticoagulation was not prescribed. On post-procedure day one, the patient's ammonia levels decreased to $55 \mathrm{mg} / \mathrm{dL}$. He was discharged on day two with normal ammonia levels and baseline mental status. On one-month follow-up, a doppler hepatic ultrasound was obtained demonstrating persistent occlusion of the CPSS with patent hepatopetal PV flow and a patent IVC. (Fig. 4) At one-year follow-up, the patient was unable to comply with ordered laboratory and ultrasound studies due to significant apprehension and need for sedation. Given the patient's excellent clinical status, ammonia testing and follow-up ultrasound was deferred. The patient's mother reports dramatic improvement in his learning skills and energy levels greater than one-year post-procedure. No additional surgical or endovascular interventions have been required.

\section{Discussion/Conclusion}

CPSS are rare intrahepatic or extrahepatic vascular malformations redirecting blood flow from the portal circulation to the systemic circulation, bypassing the liver. [2] Extrahepatic portosystemic shunts (EPSS) or "Abernethy malformations" have aberrant connections between the porto-mesenteric vasculature before PV branching and a

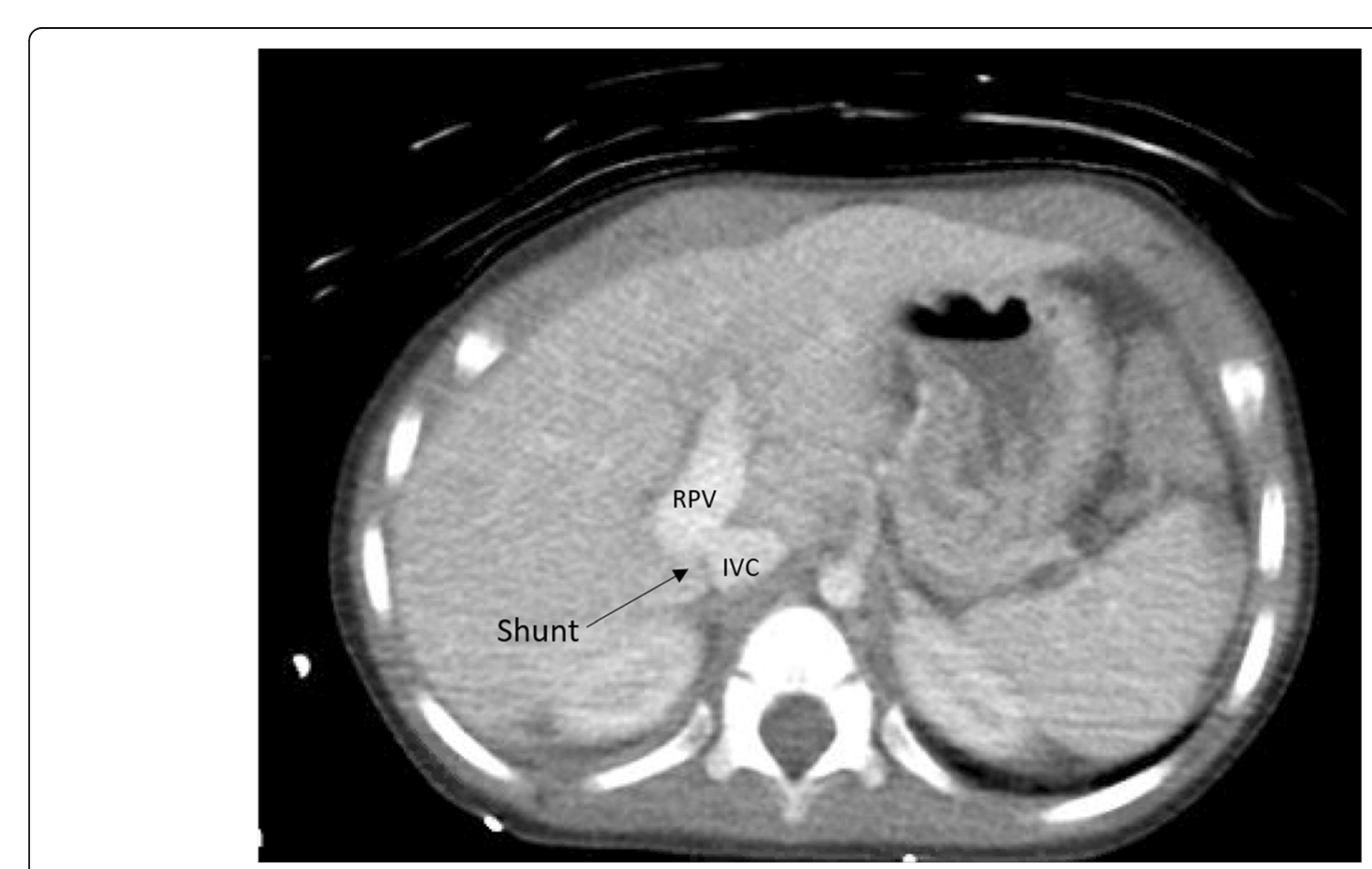

Fig. 1 Pre-procedure imaging: Axial CT image demonstrating a portosystemic shunt (black arrow) between the right portal vein (RPV) and inferior vena cava (IVC) (labeled) 


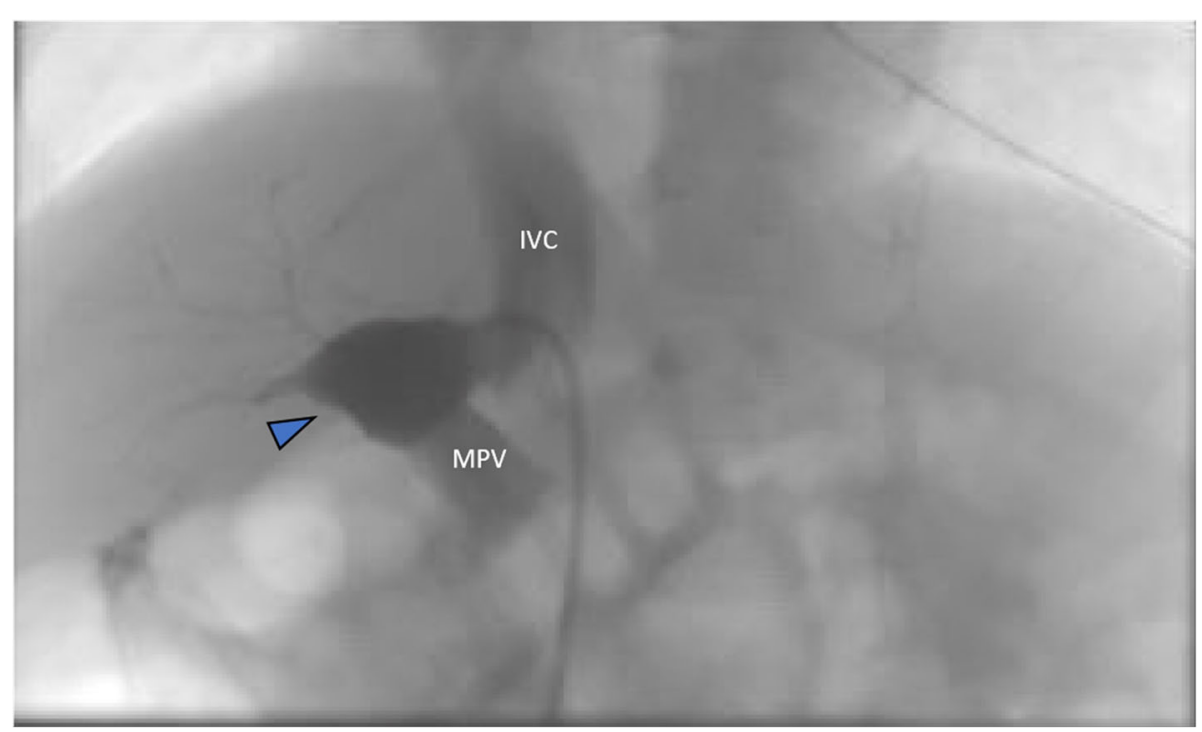

Fig. 2 Fluoroscopic evidence of CPSS. Contrast injection upon cannulation of fistulous connection between IVC and right PV branch (blue arrowhead) with a 7F sheath. Contrast is seen flowing into the MPV (labeled) and superior portion of the IVC (labeled)

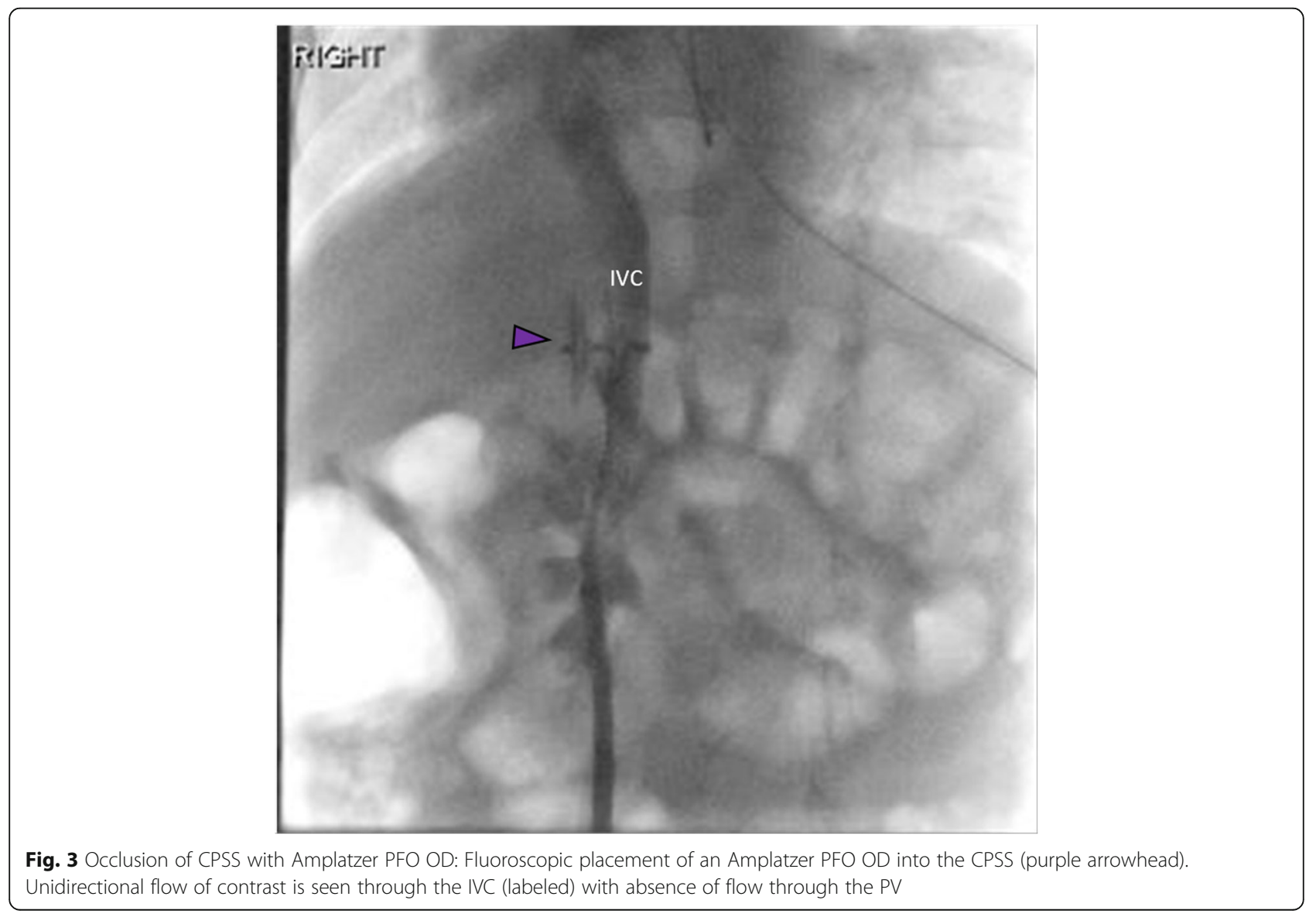



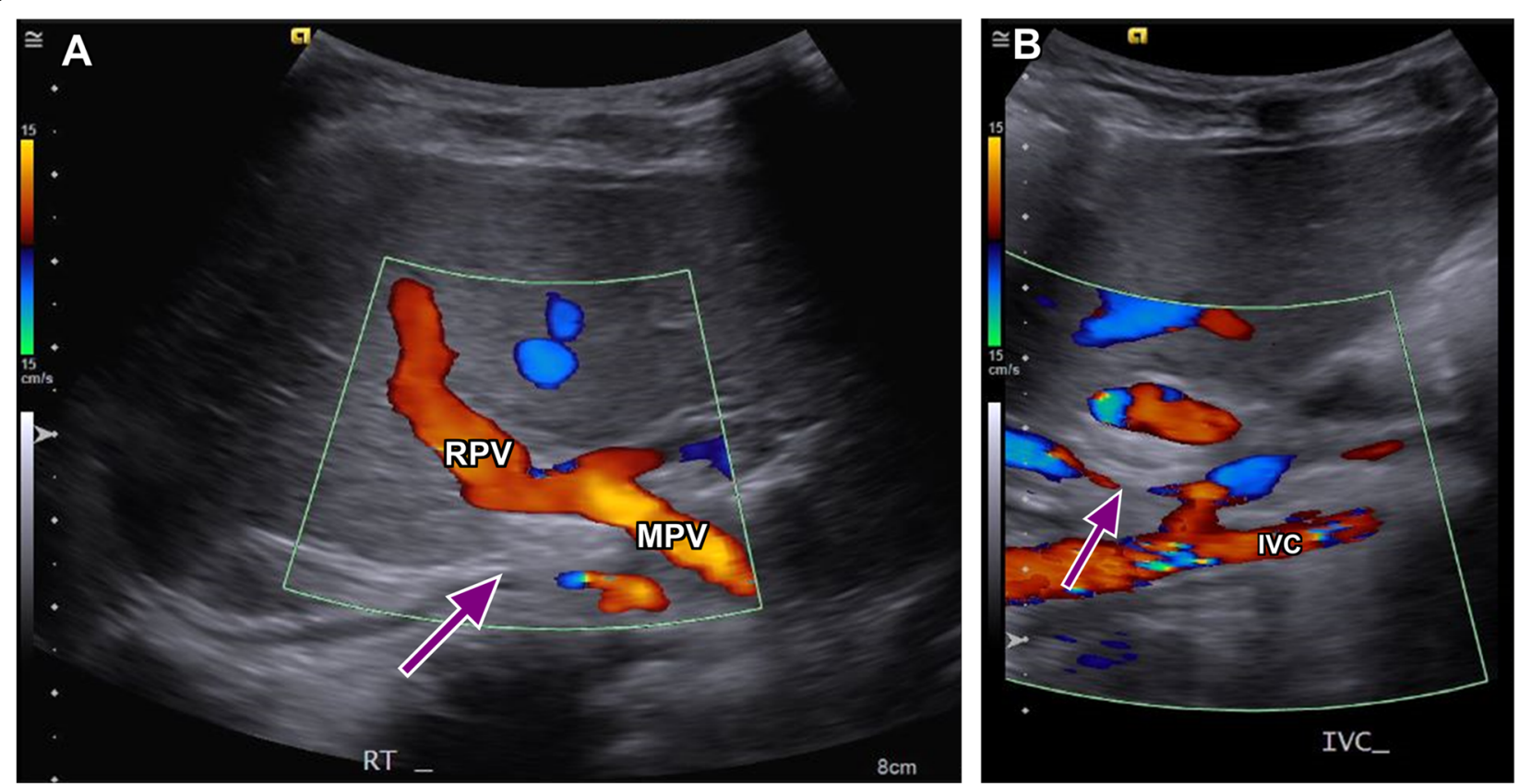

Fig. 4 Post-procedure imaging: Doppler ultrasound images of the liver at one-month follow-up. a The Amplatzer PFO OD (purple arrow) is seen within the expected location of the previously seen CPSS with patent hepatopetal flow of the main portal vein (MPV) (labeled) and RPV (labeled). b The IVC (labeled) is patent

systemic vein. [5] Type 1 EPSS have no portal venous perfusion of the liver while Type 2 EPSS have partial portal perfusion of the liver. Intrahepatic shunts, are classified based on the abnormal connections between intrahepatic branches of the portal vein and the hepatic veins or IVC. $[5,6]$ There are four subtypes which include: a single large vessel connecting the right portal vein to the IVC (type 1), localized peripheral connections between peripheral PV branches and the hepatic veins in a single hepatic segment (type 2), an aneurysmal connection between a peripheral PV and hepatic vein (type 3), and localized peripheral connections between peripheral PV branches and the hepatic veins in bilateral hepatic lobes (type 4). [5, 7] Our patient was classified as a type 1 , intrahepatic CPSS.

Doppler ultrasound is the main mode of diagnosis of CPSS. [3] Pre-procedural CT angiography and magnetic resonance angiography are often used to further evaluate complex anatomy. Shunt type, location, degree of function, patient age, severity of symptoms, and complication risks are several considerations when planning treatment. [8] To date, no standard treatment options exist. Given the variability of treatment options, this case study seeks to describe when endovascular approach with an Amplatzer PFO OD is appropriate and how it can successfully be utilized to treat a large type 1 intrahepatic CPSS.

Asymptomatic patients diagnosed with an incidental finding of intrahepatic shunt prenatally or in early infancy should be monitored for a year before definitive intervention, as many intrahepatic CPPS involute by this time. [9] Symptomatic patients, such as our patient, require immediate treatment to avoid complications associated with encephalopathy and liver dysfunction. $[8,10]$ Shunt type also determines treatment approach. Many intrahepatic CPSS can be treated with endovascular occlusion or surgical ligation given the presence of other hepatic PV perfusion. For patients with a type 1 EPSS, liver transplantation is required for definitive treatment, while for type 2 EPSS, embolization remains a noninvasive treatment option. [5]

Careful evaluation of the shunt anatomy helps to determine the appropriate embolic agent for treatment. Considering our patient's large diameter shunt and high flow, endovascular coils and detachable balloons were considered high risk for migration. Although vascular plugs have frequently been used for treatment of CPSS, few case reports describe the use of the Amplatzer PFO OD. $[3,11,12]$ Due to near parallel anatomical alignment between the right PV and IVC and as there was a circumferential hepatic parenchymal flap similar to a PFO, an Amplatzer PFO OD was determined to be a reasonable treatment option. The device's double disc design enabled placement of one disk in the right PV and the second in the IVC as it flanked the flap. Careful deployment of the device between the two vessels was ensured to avoid fatal outcomes by occlusion of either the right PV or IVC. This device was also chosen in part 
due to its ease of relocation and retrievability in case of improper positioning. Suboptimal anatomy including an end-to-side shunt or diminutive IVC and portal venous branches would preclude the use of an Amplatzer PFO OD.

Traditionally, surgical ligation has been the main therapeutic treatment for shunts with high flow rates; however, when possible, percutaneous approaches can offer a less invasive and rapid correction of symptoms. [8] An Amplatzer PFO OD should be considered in endovascular treatment of a large CPPS when the anatomy is amenable.

\section{Acknowledgements}

11. Not applicable.

\section{Authors' contributions}

Writing: Shnayder and Dervishi. Reviewing: Shnayder, Jo, and Pomerantz. Final approval: All authors.

\section{Funding}

This study was not supported by any funding.

Availability of data and materials

Not applicable.

Ethics approval and consent to participate

For this type of study, formal consent is not required.

\section{Consent for publication}

Written informed consent was obtained from the patient's mother for publication of this case report and any accompanying images.

\section{Competing interests}

The authors declare that they have no conflicts of interest

\section{Author details}

'Department of Radiology; Division of Vascular and Interventional Radiology, University of Michigan Health System, 1500 E. Medical Center Dr, B1D502, 48109-5030 Ann Arbor, MI, USA. ${ }^{2}$ American University of the Caribbean

School of Medicine, Cupecoy, St. Maarten.

Received: 19 October 2020 Accepted: 2 January 2021

Published online: 11 January 2021

References

1. Bernard O, Franchi-Abella S, Branchereau S, Pariente D, Gauthier F Jacquemin E (2012) Congenital Portosystemic Shunts in Children: Recognition, Evaluation, and Management. Semin Liver Dis 32(04):273-287. https://doi.org/10.1055/s-0032-1329896

2. Sokollik C, Bandsma RHJ, Gana JC, van den Heuvel M, Ling SC (2013) Congenital portosystemic shunt: characterization of a multisystem disease. J Pediatr Gastroenterol Nutr 56(6):675-681. https://doi.org/10.1097/MPG. Ob013e31828b3750

3. Alonso J, Sierre S, Lipsich J, Questa H, Faella H, Moguillansky S (2004) Endovascular Treatment of Congenital Portal Vein Fistulas with the Amplatzer Occlusion Device. J Vasc Interv Radiol 15(9):989-993. https://doi. org/10.1097/01.RVI.0000133225.55469.BB

4. Alharbi A, Abdulrahman S, AlOtaibi M, Alomrani A, Arabi M (2017) Congenital Extrahepatic Portosystemic Shunt Embolization with the Use of a Duct Occluder in a Neonate with Liver Dysfunction and Hyperammonemia. J Vasc Interv Radiol 28(9):1291-1293. https://doi.org/10. 1016/j.jvir.2017.05.016

5. Alonso-Gamarra E, Parrón M, Pérez A, Prieto C, Hierro L, López-Santamaría M (2011) Clinical and Radiologic Manifestations of Congenital Extrahepatic Portosystemic Shunts: A Comprehensive Review. RadioGraphics 31(3):707722. https://doi.org/10.1148/rg.313105070
6. Gallego C, Miralles M, Marín C, Muyor P, González G, García-Hidalgo E (2004) Congenital Hepatic Shunts RadioGraphics 24(3):755-772. https://doi.org/10. $1148 /$ rg. 243035046

7. Park JH, Cha SH, Han JK, Han MC (1990) Intrahepatic portosystemic venous shunt. AJR Am J Roentgenol 155(3):527-528. https://doi.org/10.2214/ajr.155. 3.2117349

8. Papamichail M, Pizanias M, Heaton N (2018) Congenital portosystemic venous shunt. Eur J Pediatr 177(3):285-294. https://doi.org/10.1007/s00431017-3058-x

9. Paganelli M, Lipsich JE, Sciveres M, Alvarez F (2015) Predisposing Factors for Spontaneous Closure of Congenital Portosystemic Shunts. J Pediatr 167(4): 931-935.e12. doi:https://doi.org/10.1016/j.jpeds.2015.06.073

10. Asymptomatic Intrahepatic Portosystemic Venous Shunt: To Treat or Not To Treat? Accessed 27 Oct 2019 https://www.ncbi.nlm.nih.gov/pmc/articles/ PMC5001872/

11. Lee SA, Lee YS, Lee KS, Jeon GS (2010) Congenital Intrahepatic Portosystemic Venous Shunt and Liver Mass in a Child Patient: Successful Endovascular Treatment with an Amplatzer Vascular Plug (AVP). Korean J Radiol 11(5):583-586. https://doi.org/10.3348/kjr.2010.11.5.583

12. Power AH, Bjarnason $H$ (2012) Large spontaneous intrahepatic portalsystemic venous shunt treated with coil and Amplatzer vascular plug embolization. Perspect Vasc Surg Endovasc Ther 24(2):90-94. https://doi.org/ $10.1177 / 1531003512455223$

\section{Publisher's Note}

Springer Nature remains neutral with regard to jurisdictional claims in published maps and institutional affiliations.

\section{Submit your manuscript to a SpringerOpen ${ }^{\circ}$ journal and benefit from:}

- Convenient online submission

- Rigorous peer review

- Open access: articles freely available online

- High visibility within the field

- Retaining the copyright to your article

Submit your next manuscript at $\boldsymbol{\nabla}$ springeropen.com 